\title{
IMPLEMENTASI TEORI SUPER PADA PROGRAM LAYANAN BIMBINGAN DAN KONSELING KARIR UNTUK MAHASISWA PERGURUAN TINGGI
}

\author{
Anaway Irianti Mansyur ${ }^{1}$ Dini Chairunnisa ${ }^{2}$ Dede Rahmat Hidayat ${ }^{3}$ \\ Email:dinurfa08@gmail.com ${ }^{1}$ \\ Prodi Bimbingan dan Konseling, Pasca Sarjana Universitas Negeri Jakarta ${ }^{1,2,3}$
}

\begin{abstract}
This literature study of guidance and counseling service programs in high school careers aim to be able to plan careers in the future. Many challenges will be faced by students in determining careers, including career uncertainty, access to information and career development programs, and economic and technological challenges. To anticipate the challenges of the hands it is necessary for universities to provide optimal service to the development of student careers. The existence of a super theory career guidance program that focuses on developing vocational identity (vocational identity) in early adulthood, is expected to help early adults in developing vocational identities as a whole, so that adolescents avoid the confusion of role confusion, especially the role of vocational identity.
\end{abstract}

Keywords: Theory Super, Guidance And Counseling, Career

\section{PENDAHULUAN}

Mahasiswa merupakan masa dimana secara individu mulai berfikir masa depannya dalam perencanan karir. Karir sebagai sebuah aspek yang sangat penting dalam kehidupan manusia. Kata karier (career) lebih menunjuk pada pekerjaan atau jabatan yang ditekuni dan diyakini sebagai panggilan hidup, yang meresapi seluruh alam pikiran dan perasaan seseorang, serta mewarnai seluruh gaya hidupnya (Winkel, 1991). Menurut (Herr, 1996) pekerjaan memiliki peran yang sangat besar dalam memenuhi kebutuhan hidup manusia. Hal ini sesuai dengan yang di jelaskan Maslow (dalam Alwisol (2009:201) yang menyatakan bahwa variasi kebutuhan manusia dipandang tersusun dalam bentuk hirarki atau berjenjang, setiap jenjang kebutuhan dapat dipenuhi hanya kalau jenjang sebelumnya telah (relatif) terpuaskan. Supaya kebutuhan Penelitian Levinson (dalam Isaacson, 1985) menunjukkan bahwa komponen terpenting dari kehidupan manusia dewasa adalah: (1) keluarga, dan (2) pekerjaan. Dua komponen tersebut sangat menentukan kebahagian hidup manusia, sehingga tidak mengherankan jika masalah pekerjaan dan keluarga praktis menyita seluruh perhatian, energi, dan waktu orang dewasa. Karir akan terus berkembang sepanjang kehidupan manusia.

Salah satu rentang usia yang paling penting dalam perkembangan karir adalah pada usia 18-25 tahun. Pada rentang usia ini keputusan-keputusan mengenai studi lanjutan akan berpengaruh besar terhadap karir seseorang (Super dalam Sharf, 
1992). Implementasi program layanan BK karir dalam fase ini menjadi hal yang sangat penting, karena pada usia inilah keputusan-keputusan mengenai karir diambil oleh seorang individu. Individu yang matang akan melakukan pilihanpilihan karir yang tepat bagi dirinya dengan mempertimbangkan berbagai aspek yang terdapat pada dirinya. Sementara individu yang tidak matang sangat memungkinkan melakukan kesalahan dalam pengambilan keputusan karir (Hidayat \& Prabowo, 2019).

Pada dasarnya di perguruan tinggi tidak merupakan bagian sistem pendidikan wajib, sehingga kuliah di perguruan tinggi merupakan suatu pilihan yang disengaja atau mungkin bisa di rencanakan sesuai keinginan. Pada penelitian yang ditemukan Kramer, dkk (Herr, 1996) terhadap mahasiswa Universitas Cornell ditemukan $48 \%$ mahasiswa laki-laki dan $61 \%$ mahasiswa perempuan mengalami masalah dalam pilihan dan perencanaan karir. Penelitian lain menemukan bahwa sebagian mahasiswa yang memasuki perguruan tinggi di Amerika menginginkan adanya pendampingan dalam perencanaan karir atau pilihan karir.

Dari penelitian tersebut ditemukan betapa butuhnya mahasiswa terhadap pembimbingan (assistance) terhadap karir yang akan dicapai. Agus Rianto (2006) mengemukakan banyak tantangan yang akan dihadapi mahasiswa dalam menentukan karir, diantaranya adalah ketidak pastian karir, pengaksesan informasi dan program pengembangan karir, dan tantangan-tantangan ekonomi dan teknologi. Untuk mengantisipasi tantangan-tangan ini perlu bagi perguruan tinggi untuk memberikan pelayanan yang optimal terhadap perkembangan karir mahasiswa.

Mahasiswa yang masuk di perguruan tinggi telah menetukan pilihannya pada program studi atau jurusan berdasarkan pengetahuan, minat dan bakat serta jenis pekerjaan yang akan diembannya setelah menanatkan pendidikannya. Pendidikan perguruan tinggi dalam program studi telah mempersiapkan paket mata kuliah yang ampunya berdasarkan kurikulum yang harus diselesaikan mahasiwa dalam waktu 4 tahun untuk tingkat strata (S1).

Super menjelaskan bahwa berkenaan dengan karir individu seusia mahasiswa (18-25 tahun) telah sampai pada tahap spesifikasi dan implementasi preferensi dalam pekerjaan. Dalam tugas-tugas perkembangan, Menurut (Brown, 2005) Teori Super menjelaskan mengenai enam peran kehidupan yaitu homemaker (pengurus rumah tangga), pekerja, citizen (warga negara), leisurite (waktu dan tenaga yang digunakan seseorang untuk melakukan kegiatan rekreasional/waktu luang), pelajar dan anak. Variasi peran 
dalam kehidupan individu digambarkan Super dalam Super's rainbow. Dalam Super's rainbow, masing-masing peran dapat didefinisikan sebagai waktu dan tenaga yang digunakan dalam menjalani peran yang dimaksudkan. Peran-peran ini saling berinteraksi dan saling mempengaruhi.

Akhmad Sudrajat

menjelaskan bahwa pada periode mahasiswa dapat digolongkan pada masa remaja akhir sampai masa dewasa awal atau dewasa madya, yang intinya pada masa ini merupakan pemantapan pendirian hidup, sehingga tugas perkembangan yang berhubungan dengan karir, yaitu memilih dan mempersiapkan karir masih menjadi tugas perkembangan mahasiswa, yang pada tahap selanjutnya (dewasa awal), tugas perkembangannya akan menjadi : seorang yang mampu untuk memilih pasangan; selanjutnya mampu untuk belajar hidup dengan pasangan. Kemudian memulai hidup dengan pasangan; Mahasiswa juga sudah seharusnya mampu memelihara dan menjaga anak; Mampu untuk mengelola rumah tangga.;setelah itu memulai bekerja; Mengambil tanggung jawab sebagai warga Negara; dan menemukan suatu kelompok yang serasi.

Perkembangan karir remaja atau dewasa awal yang digunakan dalam program bimbingan karir berbasis pada teori Super (Cramer, 1992) dalam konsep life stages. Super meringkas konsep life stages ke dalam 12 proposisi. Berdasakan 12 proposisi tersebut, Super membagi tahap perkembangan karir menjadi lima tahapan yaitu: a) tahap pertumbuhan (growth); b) tahap eksplorasi (exploration); c) tahap pendirian (establishment); d) tahap pemeliharaan (maintenance); d) dan e) tahap kemunduran (decline) (Super dalam Sharft, 1992). Menurut pendapat tersebut, maka tahap pekembangan karir masa remaja atau dewasa awal berada pada tahap explorasi (exploration) Pada tahapan ini pula menurut Savickas (Savickas, 2002) individu mencari makna dari diri sebagai upaya untuk menentukan identitas vokasional.

Karakteristik perkembangan karir remaja atau dewasa awal berada pada tahap eksplorasi (usia 15-24 tahun). Tahap eksplorasi ditandai dengan mulai melakukan penelaahan diri (selfexamination), mencoba membagi berbagai peranan, serta melakukan penjelajahan pekerjaan atau jabatan baik di sekolah, pada waktu senggang, maupun melalui sistem magang. Dengan adanya program Bimbingan Karir berbasis teori Super yang fokus dalam mengembangkan identitas vokasional (vocational identity) remaja, diharapkan dapat membantu remaja dalam mengembangkan identitias vokasional secara utuh, agar remaja terhindar dari kebingungan peran identitas (role 
confusion) khususnya peran identitas vokasional.

Berkenaan dengan alasan-alasan individu untuk memasuki perguruan tinggi di Amerika, Herr (1996) mengemukakan temuan-temuan alasan sebagai berikut: Kepuasan diri yang meliputi pencarian terhadap identitas diri dan pemenuhan diri; Mengejar karir dalam hal ini mahasiswa memandang pendidikan di perguruan tinggi sebagai alat untuk mencapai tujuan profesi atau pekerjaan tertentu, dalam hal ini perguruan tinggi dianggap sebagai alat/cara yang dapat ditempuh untuk mencapai tujuan yang diinginkan oleh individu pada kehidupannya dimasa akan datang; dan Untuk menghindar. Hal ini dilakukan mahasiswa yang menempuh pendidikan di perguruan tinggi sebagai jalan untuk menghindari sesuatu hal (wajib militer, keharusan bekerja), dan bukan karena sesuatu hal yang positif dan keinginan tidak sungguh-sungguh berasal dari hatinya. Penelitian yang dilakukan Clark \& Trow dalam (Herr, 1996) ditemukan ada empat budaya mahasiswa yang dominan, yaitu: a) Collegiate: Budaya ini berkenaan dengan keinginan mahasiswa yang mengejar kesenangan, seperti: bermain baseball, futball, catur dll. Mahasiswa tidak serius dalam menjalani perkuliahannya. Jika dikaitkan dengan trilogy sukses yang dikemukakan
(Prayitno, 2007), mahasiswa yang memiliki tipe budaya/kebiasaan seperti ini cenderung hanya mengejar sukses dalam bidang social. b)Vokasional: Berkenaan dengan pengejaran keterampilanketerampilan untuk dapat digunakan dalam bekerja pada masa akan datang,c) Akademik : Tipe ini berkenaan dengan pengejaran pengetahuan, mahasiswa yang memiliki budaya seperti ini mengedepankan kegiatan akademik untuk mencapai tujuan yang diinginkan, d) Non Konformis: Tipe ini berkenaan dengan pengejaran identitas pribadi yang sesuai/cocok.

Dalam hal kelas sosio-ekonomis, ada suatu hubungan linier antara penghasilan keluarga dengan keberadaan anak di perguruan tinggi, jika penghasilan keluarga meningkat maka kesempatan anak-anak untuk memasuki pendidikan di perguruan tinggi juga meningkat. Hal ini menyebabkan sekolah kejuruan mulai ditinggalkan. Secara tradisional, perguruan tinggi dipandang sebagai alat untuk melakukan mobilitas ke atas (Herr, 1996) Selanjutnya, kebanyakan orang memilih pendidikan di perguruan tinggi dikarenakan mereka merasa akan mendapat pengembalian-pengembalian, baik berupa kepribadian, maupun dalam hal keuangan. Ini tidak bisa dipungkiri bahwa orang menuntut ilmu untuk 
memiliki kehidupan yang baik di masa akan datang.

\section{METODE PENELITIAN}

Penelitian ini menggunakan studi pustaka yang berarti dilakukan berdasarkan atas karya tertulis termasuk hasil penelitian yang telah maupun yang belum di publikasikan (Embun, 2012).

Dalam studi literature ini mencari referensi teori yang relefan berisikan tentang 'teori super', 'bimbingan dan konseling', dan 'pengembangan karir mahasiswa'. Referensi ini didapat melalui buku, jurnal, artikel laporan penelitian dan situs-situs di internet. Berdasarkan penelitian dari Zed (2014) penelusuran pustaka tidak hanya untuk langkah awal menyiapkan kerangka penelitian namun sekaligus memanfaatkan sumber-sumber perpustakaan untuk memperoleh data penelitian. Disisi lain, review literature ini bertujuan untuk membangun dan mengkonstruksi konsepsi secara lebih kuat berbasis penelitian-penelitian empiris yang pernah dilakukan (Tjahjono, 2008). Hasil dari studi literature ini untuk mengkoleksikan referensi yang relefan dengan perumusan masalah yang ada. Sehingga dapat memperkuat permasalahan serta sebagai dasar teori dalam melakukan studi lanjutan terkait implementasi teori super pada program layanan bimbingan dan konseling karir untuk mahasiswa perguruan tinggi.

\section{HASIL DAN PEMBAHASAN}

\section{Program Perencanaan Karir Di Perguruan Tinggi}

Praktisi bimbingan dan konseling di Korea didorong untuk secara aktif mengatasi persepsi klien tentang pengaruh keluarga sehubungan dengan mencapai karier dan kehidupan yang memuaskan secara lebih umum. Melakukan hal itu dapat membantu mahasiswa merasa dipahami, divalidasi, dan diberdayakan untuk menavigasi pengaruh keluarga dan rencana maupun keinginan terkait karier individu. Penelitian yang kembangkan oleh Kim, Ahn dan Fouad (2015) menunjukkan bahwa baik orang dewasa muda dan orang tua mereka merasa perlu terbuka dalam melakukan komunikasi di antara anggota keluarga tentang memfasilitasi pengembangan karir. Sehingga pada saat di dunia perkuliahan mereka hanya tinggal mengasah kemampuan dan arah karir yang ingin dituju.

Dari hasil penelitian Stebleton dan Diamond (2018) mahasiswa tahun pertama masuk perguruan tinggi dengan keprihatinan signifikan tentang karir dan pengambilan keputusan utama, termasuk pertanyaan tentang tujuan, panggilan, dan makna. Beberapa mahasiswa memiliki kesempatan untuk secara aktif mengeksplorasi dan terlibat dalam proses refleksi tetapi banyak yang tidak. 
Profesional pendidikan tinggi perlu mengidentifikasi dan memperluas sumber daya untuk menyediakan inisiatif pengembangan karir ini khususnya mahasiswa baru sebagai ilmu untuk mengembangkan karirnya. Peneliti menganjurkan bahwa pengembangan karir, eksplorasi, dan refleksi kejuruan selama tahun pertama harus dipandang sebagai praktik berdampak tinggi yang potensial. Untuk memenuhi tujuan tersebut peneliti menguraikan tiga strategi untuk memperluas kesempatan kepada lebih banyak siswa, termasuk populasi siswa yang terpinggirkan secara historis. Strategi-strategi tersebut meliputi (a) opsi yang diperluas untuk peluang perencanaan karir, termasuk kursus untuk kredit dan non-kredit, (b) terus membayangkan kembali peran layanan karir untuk rentang populasi siswa yang lebih luas, dan (c) menanamkan karier inisiatif eksplorasi menjadi pengalaman tahun pertama. Pekerjaan mendidik siswa tahun pertama seputar pengembangan karir dan eksplorasi adalah pekerjaan kolektif, dan upaya harus melibatkan banyak pemangku kepentingan.

Di sisi lain, hasil penelitian Wong dan Kaur (2018) menguji peran proses identitas kejuruan dan keyakinan motivasi di antara 216 mahasiswa sarjana (afektif, perilaku dan kognitif). Melalui analisis regresi, eksplorasi karir yang mendalam ditemukan hubungan yang positif dengan variabel keterlibatan mahasiswa, sementara keraguan karir muncul sebagai prediktor negatif. Identifikasi dengan komitmen juga ditemukan berhubungan positif dengan keterlibatan afektif dan kognitif mahasiswa, tetapi bukan keterlibatan perilaku. Selain itu, nilai persepsi mahasiswa dalam kegiatan akademik memainkan peran penting dalam memediasi hubungan ini. Terlepas dari asosiasi yang signifikan, proses identitas kejuruan lainnya (penjelajahan karir yang luas, komitmen dan fleksibilitas karier) dan keyakinan motivasi (kepercayaan kompetensi dan biaya yang dirasakan) masing-masing gagal bertindak sebagai prediktor dan mediator, seperti yang dihipotesiskan. Meskipun demikian, penelitian tersebut menunjukkan pentingnya pengembangan identitas kejuruan dalam pembelajaran mahasiswa sarjana, dan menyarankan perlunya lebih banyak intervensi identitas atau layanan konseling karir dalam konteks perguruan tinggi dan pra-universitas.

$$
\text { Hasil analisis deskriptif }
$$
menunjukkan bahwa pengembangan karir yang diinginkan oleh perempuan lebih tinggi, dibandingkan dengan rekan-rekan pria. Mereka lebih tertarik dan memiliki self-efficacy yang lebih tinggi pada pekerjaan yang melibatkan orang-orang dan gagasan (yaitu, tipe Artistik dan Sosial 
di Teori Holland). Mahasiswa perempuan juga ditemukan lebih cenderung memilih pekerjaan yang melibatkan membantu orang lain dan mengekspresikan diri. Sebaliknya, mahasiswa pria lebih tertarik, memiliki self-efficacy yang lebih tinggi, dan lebih cenderung memilih pekerjaan melibatkan data dan hal-hal (atau Realistis, Investigatif, Enterprising, dan Konvensional dalam kode Holland). Perbedaan gender lainnya ada pada hasilnya dengan anak perempuan menunjukkan lebih banyak keinginan untuk melakukan sesuatu hal yang menolong (Tang, Pan, \& Newmeyer, 2008).

Perencanaan karir sebagai bagian penting dari keseluruhan kegiatan di perguruan tinggi. Rangkaian Model Untuk Program perencanaan karir diperguruan tinggi yaitu: Orientasi kesadaran, assesmen diri, penjajakan karir., membuat tujuan karir, pengalaman kerja, konteks karir, tersedianya dunia kerja, penempatan dan Alumi. Sistem penyampaian dalam layanan bimbingan dan konseling karirr dengan cara : layanan orientasi, layanan Informasi, layanan penempatan dan penyaluran, konseling perorangan, dan bimbingan dan konseling kelompok. Berikut ini table program perencanaan Karir mahasiswa perguruan tinggi,

Tabel 1. Program Perencanaan Karir Mahasiswa Perguruan Tinggi

\begin{tabular}{|c|c|c|c|}
\hline $\mathbf{N}$ & Program Karir & $\begin{array}{c}\text { Sistem } \\
\text { Penyampaian }\end{array}$ & Pelaksana \\
\hline 1. & $\begin{array}{l}\text { Melakukan seminar karir } \\
\text { dengan melibatkan lembaga } \\
\text { penerima tenaga kerja } \\
\text { (konsumen) } \\
\text { mahasiswa dan PT. }\end{array}$ & $\begin{array}{l}\text { Layanan } \\
\text { Informasi }\end{array}$ & $\begin{array}{l}\text { Dosen } \\
\text { Bimbingan } \\
\text { dan } \\
\text { Konseling / } \\
\text { Konselor }\end{array}$ \\
\hline 2. & $\begin{array}{l}\text { Melakukan aplikasi } \\
\text { Instrumen, sebagai balikan } \\
\text { bagi mahasiswa dalam } \\
\text { upaya pemahaman dirinya. }\end{array}$ & $\begin{array}{l}\text { Layanan } \\
\text { Penempatan } \\
\text { dan } \\
\text { penyaluran }\end{array}$ & $\begin{array}{l}\text { Dosen } \\
\text { Bimbingan } \\
\text { dan } \\
\text { Konseling } \\
\text { Konselor }\end{array}$ \\
\hline 3. & $\begin{array}{l}\text { Menyusun Program Intensif } \\
\text { yang dapat memberikan } \\
\text { pengalaman dalam beberapa } \\
\text { disiplin ilmu }\end{array}$ & $\begin{array}{l}\text { Bimbingan } \\
\text { kelompok }\end{array}$ & $\begin{array}{l}\text { Dosen } \\
\text { Bimbingan } \\
\text { dan } \\
\text { Konseling } \\
\text { Konselor }\end{array}$ \\
\hline 4. & $\begin{array}{l}\text { Menugaskan mahasiswa } \\
\text { melakukan program } \\
\text { lapangan dengan interview } \\
\text { kepada karyawan suatu } \\
\text { pekerjaan. }\end{array}$ & $\begin{array}{l}\text { Layanan } \\
\text { Penempatan } \\
\text { dan } \\
\text { Penyaluran }\end{array}$ & $\begin{array}{l}\text { Dosen } \\
\text { Bimbingan } \\
\text { dan } \\
\text { Konseling } \\
\text { Konselor }\end{array}$ \\
\hline 5. & $\begin{array}{l}\text { Kunjungan perpustakaan, } \\
\text { bursa kerja. }\end{array}$ & $\begin{array}{l}\text { Layanan } \\
\text { Orientasi }\end{array}$ & $\begin{array}{l}\text { Dosen } \\
\text { Bimbingan } \\
\text { dan } \\
\text { Konseling } \\
\text { Konselor }\end{array}$ \\
\hline 6 & $\begin{array}{l}\text { Konselor menginformasikan } \\
\text { berbagai jenis dan } \\
\text { persyaratan serta berbagai } \\
\text { macam pekerjaan yang } \\
\text { mungkin dapat dilamar } \\
\text { mahasiswa setelah tamat } \\
\text { kuliah. }\end{array}$ & $\begin{array}{l}\text { Bimbingan } \\
\text { Informasi }\end{array}$ & $\begin{array}{l}\text { Dosen } \\
\text { Bimbingan } \\
\text { dan } \\
\text { Konseling } \\
\text { Konselor }\end{array}$ \\
\hline 7 & $\begin{array}{l}\text { Mengadakan silaturahmi } \\
\text { Alumi yang sudah } \\
\text { mempunya pengalaman } \\
\text { bekerja setelah taman } \\
\text { perguruan tinggi untuk } \\
\text { termotivasi terhapa karir. }\end{array}$ & $\begin{array}{l}\text { Layanan } \\
\text { Informasi }\end{array}$ & $\begin{array}{l}\text { Dosen } \\
\text { Bimbingan } \\
\text { dan } \\
\text { Konseling } \\
\text { Konselor }\end{array}$ \\
\hline
\end{tabular}

Program layanan BK karir di perguruan tinggi bertujuan untuk membantu mahasiswa memahami perencanaan karir dan proses penempatan setelah menamatkan perguruan tinggi di masa depan. Sukardi (1989), adalah agar siswa dapat 1) meningkatkan pengetahuan tentang dirinya sendiri (self-concept); 2) meningkatkan pengetahuannya tentang 
dunia kerja; 3) mengembangkan sikap dan nilai diri dalam menghadapi pilihan lapangan kerja dalam persiapan memsukinya; 4) meningkatkan ketrampilan berpikir agar mampu mengambil keputusan tentang jabatan yang sesuai dengan dirinya dan tersedia dalam dunia kerja; dan 5) menguasai ketrampilan dasar yang penting dalam pekerjaan.

\section{PENUTUP}

Super membuat pandangan tentang perkembangan karier yang berlingkup sangat luas, karena perkembangan jabatan itu dipandang sebagai suatu proses yang mencakup banyak faktor. Faktor tersebut untuk sebagian terdapat pada individu sendiri dan untuk sebagian terdapat dalam lingkungan hidupnya yang semuanya berinteraksi satu sama lain dan bersamasama membentuk proses perkembangan karier seseorang. Pilihan jabatan merupakan suatu perpaduan dari aneka faktor pada individu sendiri seperti kebutuhan, sifat-sifat kepribadian, serta kemampuan intelektual, dan banyak faktor di luar individu, seperti taraf kehidupan sosial-ekonomi keluarga, variasi tuntutan lingkungan kebudayaan, dan kesempatan/kelonggaran yang muncul. Titik berat dari hal-hal tersebut diatas terletak pada faktor-faktor pada individu sendiri. Unsur yang mendasar dalam pandangan Super adalah konsep diri atau gambaran diri sehubungan dengan pekerjaan yang akan dilakukan dan jabatan yang akan dipegang (vocational selfconcept) yang merupakan sebagian dari keseluruhan gambaran tentang diri sendiri. Pandangan Super mengandung beberapa implikasi bagi pendidikan karier dan konseling karier yang sangat relevan. Konsepsi Super tentang gambaran diri dan kematangan vokasional menjadi pegangan bagi seorang tenaga kependidikan bila merancang program pendidikan karier dan bimbingan karier, yang membawa orang muda ke pemahaman diri dan pengolahan informasi tentang dunia kerja, selaras dengan tahap perkembangan karier tertentu.

\section{DAFTAR PUSTAKA}

Brown, S. 2005. Career Development and Counseling Putting Theory and Research to Work. New Jersey: John Willey; Sons.

Cramer, E. L. 1992. Career Guidance and Counseling Through the Life Span, Systematic Approuches. New York: Harper Collins Publisher.

Embun, B. (2012, April 17). Banjir Embun. Retrieved from Penelitian Kepustakaan: http://banjirembun.blogspot.co.id/20 12/04/penelitian-kepustakaan.html

Herr, E. L. 1996. Career guidance Throught the life span.Systematic approaches. Boston: Little, Brown \& Company.

Hidayat, D. R., \& Prabowo, A. S. 2019. A Career Development Program for Higher Education in Indonesia; The Strategy to Achieve Career Maturity. 1 st International Conference on 
Advanced Multidisciplinary Research (pp. 125-129). Makassar: Atlantis Press.

Kim, S., Ahn, T., \& Fouad, N. 2015. Family Influence on Korean Students' Career Decisions. Journal of Career Assessment, 24(3), 513-526.

Prayitno. 2007. Peningkatan Potensi Mahasiswa. Padang: UNP Press.

Savickas, M. B. 2002. The relation of career marturity to personality type and sosial adjusment. Journal of Career assessment, 10, 24-41.

Stebleton, M. J., \& Diamond, K. K. 2018. Advocating for career development and exploratioas a highimpact practice for first-year students. Journal of College and Character, 19 (2), 160-166

Super, D. S. 1992. Applying Career Development Theory to Counseling.
USA: Brooks/Cole Publishing Company.

Tang, M., Pan, W., \& Newmeyer, M. D. (2008). Factors Influencing High School Students' Career Aspirations. Professional School Counseling, 11(5),

Tjahjono, H. K. 2008. Studi literatur pengaruh keadilan distributif dan keadilan prosedural pada konsekuensinya dengan teknik meta analisis. Jurnal Psikologi, 35 (1)

Wong, Z. Y., \& Kaur, D. 2018. The role of vocational identitiy development and motivational beliefs inundergraduates' student engagement. Counselling Psychology Quarterly, 31(3), 294316

Zed, M. 2014. Metode Penelitian Kepustakaan. Jakarta: Yayasan Obor Indonesia 